\title{
Promotion de croissance du riz inoculé par une bactérie fixatrice d'azote, Burkholderia vietnamiensis, isolée d'un sol sulfaté acide du Viêt-nam
}

\author{
V Trân Van ${ }^{1}$, P Mavingui ${ }^{2}$, O Berge ${ }^{1 *}$, J Balandreau ${ }^{3}$, T Heulin ${ }^{1}$ \\ 1 Équipe d'écologie microbienne de la rhizosphère, centre de pédologie biologique, UPR 6831 du CNRS, \\ associée à l'université de Nancy I, BP 5, F54501 Vandcuvre-lès-Nancy cedex, France ; \\ 2 Départamento de Genetica Molecular, Centro de Investigacion sobre Fijacion de Nitrogeno, \\ Universidad Nacional Autonoma de México, Apartado postal 565-A, Cuernavaca, Mor, Mexique ; \\ ${ }^{3}$ Laboratoire d'écologie microbienne du sol, URA 1977 du CNRS, université Claude-Bernard, \\ 43, boulevard du 11-Novembre-1918, F69622 Villeurbanne, France
}

(Reçu le 1er septembre 1994; accepté le 31 janvier 1995)

\begin{abstract}
Résumé - Des essais d'inoculation du riz par une souche bactérienne fixatrice d'azote, Burkholderia vietnamiensis TVV75, ont été menés en pots sur un sol sulfaté acide du Viêt-nam, en conditions extérieures. L'effet de cette bactérie a été testé à 3 niveaux d'azote : 0, 45 et $90 \mathrm{U}$. La souche utilisée avait été au préalable isolée parmi les bactéries fixatrices d'azote les plus abondantes de la rhizosphère du riz cultivé sur ce même sol, et sélectionnée pour son activité réductrice d'acétylène et son activité de promotion de croissance sur jeune plante. Dans cet essai, l'azote était bien le facteur limitant, comme le montre clairement la réponse de la culture du riz à la fertilisation azotée. Dans ces conditions, l'inoculation bactérienne a entraîné des augmentations significatives du tallage $(12 \%)$ et de la hauteur des plantules $(8 \%)$ du peuplement herbacé en pépinière, et un accroissement significatif de la production de matières sèches racinaires et aériennes tout au long de la culture. Cette augmentation de la biomasse végétale s'est accompagnée d'une augmentation du rendement final de $20 \%$ à la récolte, expliquée par un effet de l'inoculation sur toutes les composantes du rendement. Ces résultats ouvrent la voie à des applications agronomiques très prometteuses.
\end{abstract}

promotion de croissance / Oryza sativa L = riz / Burkholderia vietnamiensis sp nov / inoculation / sol sulfaté acide / composantes du rendement / fixation d'azote / PGPR / Viêt-nam

Summary - Growth promotion of rice after inoculation with a nitrogen-fixing bacteria Burkholderia vietnamiensis isolated from an acid-sulfate soil in Vietnam. Inoculation of rice with TVV75, an $\mathrm{N}_{2}$-fixing strain of Burkholderia vietnamiensis, was conducted in a Vietnamese acid-sulfate soil in pot trials. The effect of this bacterial strain was tested for 3 nitrogen fertilizer rates, 0, 45 and $90 \mathrm{U}$ under outdoor conditions. The inoculated strain has been isolated as a member of the dominant $N_{2}$-fixing microflora in the rhizosphere of rice growing on the above-mentioned soil. It was selected because it exhibited a high acetylene reduction rate and high growth promotion on young plants. In the present experiment, nitrogen availability was the limiting factor for the growth of rice, which is clearly shown by the response of the plant to nitrogen fertilizer application in control pots. Under these conditions, bacterial inoculation resulted in significant increases in tiller number (12\%) and plant height (8\%) in nursery beds, and significant

\footnotetext{
* Correspondance et tirés à part
} 
increases were also observed in both shoot and root dry weights, throughout the growth cycle, leading to a higher final yield (20\%). These results are promising for further applications.

plant growth promotion / Oryza sativa $L=$ rice / Burkholderia vietnamiensis sp nov / inoculation / acid-sulfate soil / yield components / nitrogen fixation / PGPR / Vietnam

\section{INTRODUCTION}

De nombreux travaux ont été consacrés, ces dernières années, à l'utilisation de bactéries du sol pour l'amélioration de la croissance des plantes et la diminution des intrants coûteux et potentiellement polluants en agriculture. Ces bactéries promotrices de croissance (PGPR pour «Plantgrowth-promoting rhizobacteria») appartiennent à différents genres tels que Pseudomonas, Azospirillum, Azotobacter et Bacillus (Gaskins et al, 1985). La fixation non symbiotique de l'azote a été l'un des premiers mécanismes bactériens identifiés dans la rhizosphère des végétaux comme susceptible d'induire une augmentation de la croissance des plantes (Boddey et Döbereiner, 1988). Aussi, de nombreuses souches bactériennes fixatrices d'azote ont été isolées du sol et de la rhizosphère et inoculées à diverses espèces végétales (Jagnow, 1987 ; Rajaramamohan et al, 1987). Cependant, l'importance de la fixation d'azote non symbiotique comme source d'azote pour les plantes non légumineuses a fait l'objet de controverses ultérieures (Michiels et al, 1989). D'autres mécanismes bactériens ont alors été proposés pour expliquer la stimulation de la croissance des plantes. Ils comprennent la production de phytohormones de croissance (Lesinger et Margraff, 1979 ; Lin et al, 1983), l'induction d'une augmentation de prélèvement de phosphore (Lifshitz et al, 1987) et l'antagonisme vis-à-vis de microorganismes phytopathogènes (Kloepper et al, 1989 ; Hebbar et al, 1992), en particulier, par le biais de la compétition pour le fer (Jukevitch et al, 1992 ; Lemanceau, 1992).

Le riz (Oryza sativa $L$ ) est l'une des céréales les plus cultivées dans le monde. De nombreux auteurs ont montré que l'inoculation du riz par des bactéries PGPR (fixatrices d'azote ou non) pouvait entraîner une augmentation significative de la hauteur des plantes, des biomasses racinaires et aériennes et du rendement en grains (Subba Rao et al, 1979; Balasubramania et Kumar, 1987). Cependant, les résultats de l'inoculation apparaissaient très variables (Roger et Ladha, 1992), jusqu'à ce qu'Omar et al (1992) montrent l'importance d'une approche plus écologique, avec en particulier la nécessité de prendre en compte l'origine de la bactérie à inoculer, et le facteur qui limite effectivement la croissance de la plante dans les conditions utilisées. Ces auteurs ont montré, en Égypte, qu'on ne pouvait attendre un effet bénéfique de l'inoculation par des bactéries fixatrices d'azote qu'avec des souches adaptées aux conditions locales, et seulement lorsque le facteur limitant est l'azote.

Bien que le Viêt-nam soit parmi les premiers producteurs de riz, très peu d'études ont été entreprises jusqu'ici sur l'utilisation des bactéries PGPR en riziculture dans ce pays. L'extrapolation au Viêt-nam des travaux égyptiens semblait a priori hasardeuse, faute de connaissances précises sur les bactéries associées au riz dans les sols vietnamiens. Ceci était particulièrement vrai en ce qui concerne le milieu écologique très particulier des sols sulfatés acides qui portent une fraction importante des rizières du sud du Viêt-nam.

Avant toute chose, il a donc fallu déterminer quelles étaient les bactéries fixatrices d'azote les plus abondantes dans la rhizosphère du riz cultivé dans un sol sulfaté acide du Viêt-nam (Trân Van, 1989). Elles diffèrent des bactéries fixatrices d'azote décrites jusqu'alors. Leur étude taxonomique a conduit à la création d'une nouvelle espèce, Burkholderia vietnamiensis (Gillis et al, 1995). La capacité de la souche $B$ vietnamiensis TVV75 à augmenter la fixation d'azote et la croissance des plantes a été démontrée sur le riz à un stade jeune, au phytotron (Trân Van, 1994). L'objectif de ce travail était d'étudier, dans des conditions plus proches des conditions naturelles, l'effet de l'inoculation du riz par la souche TVV75 de $B$ vietnamiensis; nous rapportons ici les résultats obtenus dans des essais en pots, utilisant un sol sulfaté acide du Viêt-nam, du même type que le sol ayant servi à l'isolement de la souche.

\section{MATÉRIEL ET MÉTHODES}

\section{Le sol}

L'essai a été réalisé à la station agronomique rizicole de Thanh Lôc, située à $13 \mathrm{~km}$ au nord de Hô Chi Minh 
Ville. Le sol a été prélevé après la première récolte du riz au mois d'août, tamisé à $5 \mathrm{~mm}$, puis réparti dans des pots de $32,5 \mathrm{~cm}$ de diamètre et $37 \mathrm{~cm}$ de hauteur, à raison de $5 \mathrm{~kg}$ de sol sec par pot. Ce sol est sulfaté acide (Sulfi-Thionic-Fluvisol selon la classification $\mathrm{FAO}$ ) de texture argilo-limoneuse (tableau I).

\section{La souche bactérienne}

La souche fixatrice d'azote TVV75 a été isolée de la rhizosphère de plantes de riz âgées de $8 \mathrm{j}$ et cultivées en tubes sur le sol sulfaté acide en chambre climatisée. Le dénombrement et l'isolement des bactéries fixatrices d'azote de la rhizosphère (racines et sol adhérent) ont été effectués selon la méthodologie utilisant le modèle spermosphère, et décrite par Omar et al (1989). La taille du peuplement de fixateurs d'azote a été estimée à $10^{8}$ UFC (unité formant colonie)/g de matière sèche de sol rhizosphérique. Douze souches bactériennes fixatrices d'azote, dont la TVV75, ont été isolées à la dilution la plus élevée. Ces souches appartiennent donc à l'espèce dominante au sein du peuplement fixateur d'azote. Ces souches ont été récemment identifiées à une nouvelle espèce Burkholderia vietnamiensis (Gillis et al, 1995) apparentée à Pseudomonas cepacia, qui a été récemment rebaptisée Burkholderia cepacia (Yabuuchi et al, 1992).

\section{Préparation de l'inoculum bactérien}

La culture de la souche bactérienne a été réalisée dans des flacons de $250 \mathrm{ml}$ contenant $100 \mathrm{ml}$ de milieu LB modifié (bactotryptone $10 \mathrm{~g}$, extrait de levure $5 \mathrm{~g}, \mathrm{NaCl} 5 \mathrm{~g}$, eau $1000 \mathrm{ml}$, autoclavage : $20 \mathrm{~min}$ à $120^{\circ} \mathrm{C}$ ). Les flacons ont été incubés à $30^{\circ} \mathrm{C}$ sous agitation pendant $24 \mathrm{~h}$. La culture était alors en fin de phase logarithmique de croissance et a été centrifugée
20 min à $7000 \mathrm{rpm}$. Le culot bactérien a été lavé et mis en suspension dans une solution de $\mathrm{KCl}(0,85 \%)$. La concentration bactérienne estimée par comptage au microscope a été ajustée à $4 \times 10^{8} \mathrm{bact} / \mathrm{ml}$. Le contrôle de pureté de l'inoculum a été effectué par dilution étalement sur milieu PCAT : acide azélaïque $2,0 \mathrm{~g}$, tryptamine (Aldrich) $0,2 \mathrm{~g}, \mathrm{MgSO}_{4} 0,1 \mathrm{~g}, \mathrm{KH}_{2} \mathrm{PO}_{4}$ $4,0 \mathrm{~g}$, extrait de levure $0,02 \mathrm{~g}$, gélose $15 \mathrm{~g}$, eau 1000 $\mathrm{ml}, \mathrm{pH} 5,7$, autoclavage : $20 \mathrm{~min}$ à $120^{\circ} \mathrm{C}$. Ce milieu a été décrit comme sélectif pour l'espèce $B$ cepacia et permet aussi la croissance de quelques espèces apparentées, comme $B$ vietnamiensis (Burbage et Sasser, 1982).

\section{Inoculation et conduite de la culture des plantes}

Le riz a été cultivé de la façon traditionnelle au Viêtnam avec le semis en pépinière et le repiquage manuels, ce qui permet d'inoculer la plante 2 fois pendant la saison : au semis et au repiquage. Nous avons utilisé un cultivar hybride OM 5971 à cycle court (110 j) inscrit au catalogue en 1982 par l'Institut du riz du delta du Mékong. Après gonflement dans l'eau pendant $24 \mathrm{~h}$, les semences de riz ont été placées dans des sacs en lin qui ont été ensuite immergés dans l'eau. Après $48 \mathrm{~h}$, les semences prégermées avaient des racines séminales de 1 à $2 \mathrm{~cm}$. Elles ont alors été sorties des sacs et mises en contact avec l'inoculum bactérien à raison de $10^{7}$ bactéries/semence et 25 $\mathrm{ml} / 1000$ graines pendant $18 \mathrm{~h}$ à la température du laboratoire, avant d'être semées à la volée directement en pépinière en plein champ. Le nombre de $B$ vietnamiensis par graine a été contrôlé par dénombrement des UFC sur milieu PCAT après broyage. Le calcul montre que chaque semence a reçu environ $5 \times 10^{7}$ UFC. Les semences du traitement témoin ont été trempées dans une solution stérile de $\mathrm{KCl}(0,85 \%)$. Après 3 sem de croissance en pépinière, les jeunes

Tableau I. Caractéristiques physico-chimiques du sol sulfaté acide de rizière utilisé dans l'essai.

\begin{tabular}{|c|c|c|c|c|c|c|c|c|c|c|}
\hline \multirow{2}{*}{$\begin{array}{l}\text { Profondeur } \\
\text { (cm) }\end{array}$} & \multicolumn{4}{|c|}{ Granulométrie \%a } & \multirow[t]{2}{*}{$M O^{a}(\%)$} & \multirow[t]{2}{*}{$C_{\text {org }}(\%)$} & \multirow[t]{2}{*}{$N_{\text {tot }}$} & \multirow[t]{2}{*}{$C / N$} & \multirow[t]{2}{*}{$\mathrm{pH}_{\mathrm{KCl}}$} & \multirow[t]{2}{*}{$\mathrm{pH}_{\mathrm{H} 2 \mathrm{O}}$} \\
\hline & $S G$ & $S F$ & $L$ & $A$ & & & & & & \\
\hline $0-20$ & 30,0 & 16,1 & 18,0 & 36,0 & 10,17 & 5,90 & 0,28 & 21 & 4,0 & 4,2 \\
\hline
\end{tabular}

Profondeur

$(\mathrm{cm})$

$0-20$
Bases échangeables (me/100 g)

Éléments libres (\%o)

$\begin{array}{llll}\mathrm{Ca}^{++} & \mathrm{Mg}^{++} & \mathrm{K}^{+} & \mathrm{Na}^{+} \\ 2,50 & 1,80 & 0,077 & 0,65\end{array}$

$\mathrm{Fe} \quad \mathrm{Al}$

$0,116 \quad 0,088$

a Méthode densimétrique ; SG : sable grossier $(200-2000 \mu \mathrm{m})$; SF : sable fin $(50-200 \mu \mathrm{m})$; LG : limon grossier et fin $(2-50 \mu \mathrm{m}) ; A$ : argile (inférieur à $2 \mu \mathrm{m}$ ); $\mathrm{MO}$ : matière organique. 
plants ont été arrachés pour être repiqués. Bien que des différences de croissance entre les plantes inoculées et les témoins aient été visibles à l'œil, des plantes de taille et de stade comparables ont été choisies pour le repiquage afin de mesurer l'effet de la deuxième inoculation. En effet, à ce stade, les racines ont été à nouveau trempées dans l'inoculum bactérien dans les mêmes conditions qu'au semis ( $10^{7}$ bactéries/plante) et 3 plants par pot ont été repiqués.

\section{Plan d'expérience}

Le plan d'expérience est un plan complet à 2 facteurs croisés : le facteur inoculation à 2 modalités, inoculé et non inoculé, et le facteur azote à 3 niveaux : dose maximale recommandée ( $90 \mathrm{~kg} \mathrm{~N} / \mathrm{ha}$ ), demi-dose ( $45 \mathrm{~kg} \mathrm{~N} / \mathrm{ha}$ ) et témoin sans azote. Les 2 facteurs croisés conduisent à 6 traitements. Chaque traitement a été réalisé en 10 répétitions, soit un total de 60 pots (180 plantes). Le dispositif adopté est la randomisation totale. Les pots, espacés de $15 \mathrm{~cm}$, ont été placés par lignes de 10 sur une aire jouxtant les parcelles expérimentales. Les paramètres climatiques mesurés au cours des 4 mois de culture sont rapportés dans le tableau II.

\section{Fertilisation}

Les doses de fertilisants utilisées correspondent à celles couramment appliquées en culture rizicole dans la région de la station expérimentale, où s'est déroulée l'expérience. Chaque pot a reçu l'équivalent de 0,45 ou 90 unités d'N (sous forme d'urée) rapportées à la surface du pot, 71 unités de $\mathrm{P}\left(\mathrm{P}_{2} \mathrm{O}_{5}\right)$ et 108 unités de $\mathrm{K}$ (sous forme de $\mathrm{KCl}$ ). La totalité du phosphore et $1 / 3$ du potassium ont été apportés au sol avant le remplissage des pots et les $2 / 3$ du potassium restants, en début de floraison. L'apport de l'urée a été fractionné en trois apports : 1/3 au repiquage, $1 / 3$ au dixième jour après le repiquage (10 JAR) et $1 / 3$ au début de la floraison (40 JAR). Une dose de $12 \mathrm{~g}$ de chaux par pot a été apportée, au moment du repiquage, pour élever le $\mathrm{pH}$ du sol jusqu'à pH 6,0.

\section{Mesures des variables}

Les variables qui expriment la croissance du riz, ont été mesurées à différents stades du développement. Au moment du repiquage (début du tallage), la hauteur des plantes et le nombre de talles ont été mesurés respectivement sur 100 plantes par traitement. La biomasse végétale a été estimée aux stades tallage (30 JAR), début floraison (45 JAR), pleine floraison 65 (JAR), et enfin à la récolte ( $85 \mathrm{JAR})$, par le poids de matière sèche (PMS) des racines et des parties aériennes mesurés à chaque fois sur les plantes issues de 2 pots par traitement. De plus, à la récolte, le nombre de panicules, de grains pleins et le poids de 1000 grains (PMG) (14\% d'humidité) ont été déterminés sur les 4 pots restants par traitement. Le rendement $(\mathrm{g} / \mathrm{pot})$ a été calculé à partir des 2 variables, PMG et nombre de grains par pot. L'effet des 2 facteurs, apport d'engrais azoté et inoculation, a été testé sur toutes ces variables. Le traitement des données a été effectué par l'analyse de variance ou test du $\chi^{2}$, à l'aide du logiciel Statgraphics (Release 5.0, Uniware STSC, Inc). L'effet d'un facteur est déclaré significatif quand $P<0,05$ ou exceptionnellement quand $0,05<P$ $<0,10$ lorsque cela est précisé dans le texte ou dans les tableaux.

\section{RÉSULTATS}

\section{Effet précoce de l'inoculation en pépinière}

L'inoculation a augmenté significativement la hauteur et le nombre de talles des plantes en pépinière (tableaux IIla et b). En effet, à ce stade, la hauteur des plantes inoculées est en moyenne plus élevée de $8,6 \%$ que celle des témoins non inoculés. De même, à cette date, le tallage herbacé est nettement augmenté par l'inoculation, puisque $72 \%$ des plantes inoculées ont produit 2 ou 3 talles contre $60 \%$ pour les plantes témoins non inoculées.

Tableau II. Conditions climatiques a au cours de la culture.

\begin{tabular}{lcccc} 
& Août & Septembre & Octobre & Novembre \\
\hline Température moyenne $\left({ }^{\circ} \mathrm{C}\right)$ & 27,5 & 27,1 & 26,7 & 26,7 \\
Humidité moyenne $(\%)$ & 83 & 88 & 84 & 76 \\
Pluviométrie $(\mathrm{mm})$ & 254,1 & 254,1 & 367,8 & 43,7
\end{tabular}

\footnotetext{
a Données de la station météorologique de Tân Son Hòa.
} 
Tableau Illa. Effet de l'inoculation du riz par Burkholderia vietnamiensis TVV75 sur la hauteur des plantes et le tallage herbacé en pépinière sur un sol sulfaté acide du Viêt-nam.

\begin{tabular}{|c|c|c|c|c|c|}
\hline \multirow[t]{2}{*}{ Traitement } & \multirow{2}{*}{$\begin{array}{l}\text { Hauteur des plantes } \\
\qquad(\mathrm{cm})\end{array}$} & \multicolumn{3}{|c|}{ Nombre des plantes ayant } & \multirow{2}{*}{ Test de $\chi$} \\
\hline & & 1 talle & 2 talles & 3 talles & \\
\hline Témoin & $29,2 \pm 0,5$ & 40 & 43 & 17 & a \\
\hline Inoculé & $\begin{array}{c}31,6 \pm 0,9 \\
n=100\end{array}$ & 28 & 43 & 29 & $\begin{array}{c}\mathrm{b} \\
n=100\end{array}$ \\
\hline
\end{tabular}

Effet inoculation

$\mathrm{S}$

$\mathrm{S}$

Les valeurs sont des moyennes \pm intervalle de confiance $(5 \%) ; n=$ nombre de répétitions par traitement ; $\mathrm{S}$ significatif $(P<0,05)$.

Tableau Illb. Résultats de l'analyse de variance de la hauteur des plantes $(\mathrm{cm})$ du riz cultivé en pépinières.

\begin{tabular}{|c|c|c|c|c|c|}
\hline Source de variations & $D D L$ & $\begin{array}{c}\text { Somme } \\
\text { des carrés }\end{array}$ & $\begin{array}{l}\text { Carrés } \\
\text { moyens }\end{array}$ & $F$ & $\mathrm{P}$ \\
\hline \multicolumn{6}{|c|}{ Hauteur des plantes $(\mathrm{cm})$} \\
\hline Inoculation & 1 & 296,461 & 296,461 & 22,714 & 0,0000 \\
\hline Résidu & 198 & 2584,278 & 13,052 & & \\
\hline Total & 199 & 2880,739 & & & \\
\hline
\end{tabular}

Les tests $\mathrm{F}$ font intervenir le rapport entre le carré moyen des écarts du facteur étudié sur celui du résidu.

\section{Effet de la fertilisation azotée sur le développement du riz après repiquage}

L'interaction entre les 2 facteurs, azote et inoculation, n'est significative pour aucune des variables mesurées sauf le poids de matière sèche de racines à la récolte ( $85 \mathrm{JAR}$ ) (tableaux IV et $\mathrm{V}$ ), ce qui nous conduit à présenter d'abord l'effet de l'azote puis l'effet de l'inoculation. L'effet de l'azote sur ces variables est présenté dans les tableaux IV et $V$, alors que les valeurs obtenues sont présentées dans les tableaux $\mathrm{VI}$ et VII.

Les résultats reportés dans les tableaux $\mathrm{VI}$ et VII font apparaître nettement l'effet positif des apports d'azote sur le développement des plants de riz : l'effet de l'azote est significatif à tous les stades $(P<0,05)$, sauf au premier prélèvement (30 $\mathrm{j}$ après le repiquage) où seul le poids de racines est augmenté significativement par l'apport d'azote. Des augmentations ont été également obtenues à la récolte (tableau VII) sur le nombre de panicules par pot qui est significativement augmenté $(+44 \%$ entre les valeurs extrêmes). De même, l'apport d'azote a significa- tivement augmenté le nombre de grains pleins par pot $(+21 \%$ entre les valeurs extrêmes), mais avec une probabilité d'erreur $P=8,3 \%$. En revanche, la fertilisation azotée n'a aucun effet sur le poids de 1000 grains qui est une variable peu sensible à l'azote (tableau V). En conséquence, le rendement calculé est significativement augmenté $(+22 \%)$ par la fertilisation azotée, avec une probabilité d'erreur $P=7,2 \%$.

\section{Effet de l'inoculation sur la biomasse du riz après repiquage}

Les valeurs de biomasses racinaires et aériennes sont présentées dans le tableau VIII et l'effet de l'inoculation sur ces variables est présenté dans le tableau IV. L'inoculation a eu un effet plus tardif que l'engrais azoté sur ces variables. C'est seulement à la pleine floraison que les parties aériennes sont augmentées significativement $(+23 \%)$. L'effet de l'inoculation sur les biomasses racinaires n'est significatif qu'à partir de la pleine floraison $(+32 \%)$ et se maintient à la récolte $(+27 \%)$ (tableau VIII). 
Tableau IV. Résultats de l'analyse de variance des poids de matière sèche des parties aériennes et des parties racinaires après le repiquage en fonction du niveau d'azote et du traitement d'inoculation.

Source de variations

$D D L$

PA30JAR (g de matière sèche/pot)

Inoculation

Azote

Inoculation $x$ azote

Résidu

Total

1
2
2
6
11

PAS45JAR (g de matière sèche/pot)

$\begin{array}{ll}\text { Inoculation } & 1 \\ \text { Azote } & 2 \\ \text { Inoculation x azote } & 2 \\ \text { Résidu } & 6 \\ \text { Total } & 11\end{array}$

Total

11

PA65JAR (g de matière sèche/pot)

Inoculation
Azote
Inoculation $\mathrm{x}$ azote
Résidu
Total

1
2
2
6
11

PA85JAR ( $\mathrm{g}$ de matière sèche/pot)

Inoculation

Azote

Inoculation $x$ azote

Résidu

Total

1
2
2
18
23

RA3OJAR (g de matière sèche/poquet) Inoculation

Azote

1
2
2
30
35

Inoculation $x$ azote

Résidu

Total

RA45JAR (g de matière sèche/poquet)

Inoculation
Azote
Inoculation $\mathrm{x}$ azote
Résidu
Total

RA65JAR (g de matière sèche/poquet)

$\begin{array}{ll}\text { Inoculation } & 1 \\ \text { Azote } & 2 \\ \text { Inoculation x azote } & 2 \\ \text { Résidu } & 30 \\ \text { Total } & 35\end{array}$

RA85JAR (g de matière sèche/poquet)

$\begin{array}{lll}\text { Inoculation } & 1 & 15,494 \\ \text { Azote } & 2 & 7,630 \\ \text { Inoculation x azote } & 2 & 8,156 \\ \text { Résidu } & 66 & 65,329 \\ \text { Total } & 71 & 96,610\end{array}$

\section{Somme \\ des carrés \\ 3,413 \\ 434,873 \\ 23,797 \\ 346,721 \\ 808,804}

39,785

4284,699

4,356

1507,442

5836,283

690,387

3668,382

3,840

475,116

4837,724

367,775
8663,468
3,893
3007,668
12042,804

0,224

33,753

1,027

68,918

103,922

0,389

28,453

0,783

82,961

112,586

25,402
14,769
0,322
88,356
128,849

96,610
Carrés

moyens

3,413

217,437

11,898

57,787

39,785

2142,350

2,178

251,240

690,387

1834,191

1,920

79,186

8,719

0,158

8,527

0,009

0,7085

0,0176

0,9914

23,163

0,024

0,0255

0,0015

0,9761

367,775

4331,734

1,946

167,093

0,224

0,098

0,7603

16,876

7,346

2,297

0,389

0,141

5,145

0,142

0,7144

14,227

0,392

2,765

25,402

7,385

0,161

2,945

8,625

2,507

0,055

0,0063

0,0984

0,9469

0,1552

0,9884

PA30JAR, PA45JAR, PA65JAR, PA85JAR : partie aérienne 30, 45, 65, 85 j après repiquage ; RA30JAR, RA45JAR, RA65JAR, RA85JAR : partie racinaire $30,45,65,85 \mathrm{j}$ après repiquage. Les tests $\mathrm{F}$ font intervenir le rapport entre le carré moyen des écarts du facteur étudié sur celui du résidu.

15,494

3,815

4,078

0,990
15,653

0,0002

3,854

0,0261

4,120

0,0206 
Tableau V. Résultats de l'analyse de variance du rendement et de ses composantes, poids de mille grains, nombre de panicules par pot et nombre de grains pleins par pot à la récolte en fonction du niveau d'azote et du traitement d'inoculation.

\begin{tabular}{|c|c|c|c|c|c|}
\hline Source de variations & $D D L$ & $\begin{array}{l}\text { Somme } \\
\text { des carrés }\end{array}$ & $\begin{array}{l}\text { Carrés } \\
\text { moyens }\end{array}$ & $F$ & $\mathrm{P}$ \\
\hline \multicolumn{6}{|l|}{ Rendement (g/pot) } \\
\hline Inoculation & 1 & 355,278 & 355,278 & 6,614 & 0,0192 \\
\hline Azote & 2 & 327,904 & 163,952 & 3,052 & 0,0723 \\
\hline Inoculation $\mathrm{x}$ azote & 2 & 33,891 & 16,946 & 0,315 & 0,7334 \\
\hline Résidu & 18 & 966,882 & 53,716 & & \\
\hline Total & 23 & 1683,956 & & & \\
\hline \multicolumn{6}{|c|}{ Poids de 1000 grains (mg/ 1000 grains) } \\
\hline Inoculation & 1 & 14,742 & 14,742 & 4,522 & 0,0476 \\
\hline Azote & 2 & 2,425 & 1,212 & 0,372 & 0,6946 \\
\hline Inoculation $\mathrm{x}$ azote & 2 & 3,187 & 1,594 & 0,489 & 0,6213 \\
\hline Résidu & 18 & 58,687 & 3,260 & & \\
\hline Total & 23 & 79,041 & & & \\
\hline \multicolumn{6}{|c|}{ Nombre de panicules par pot (talles/pot) } \\
\hline Inoculation & 1 & 532,042 & 532,042 & 4,172 & 0,0560 \\
\hline Azote & 2 & 1011,583 & 505,792 & 3,966 & 0,0374 \\
\hline Inoculation $\mathrm{x}$ azote & 2 & 33,583 & 16,792 & 0,132 & 0,8775 \\
\hline Résidu & 18 & 2295,750 & 127,542 & & \\
\hline Total & 23 & 3872,958 & & & \\
\hline \multicolumn{6}{|c|}{ Nombre de grains pleins par pot (grains pleins/pot) } \\
\hline Inoculation & 1 & 461760,04 & 461760,04 & 3,961 & 0,0620 \\
\hline Azote & 2 & 668227,00 & 334116,50 & 2,866 & 0,0831 \\
\hline Inoculation $\mathrm{x}$ azote & 2 & 142304,33 & 71152,17 & 0,610 & 0,5540 \\
\hline Résidu & 18 & 2098329,3 & 116573,85 & & \\
\hline Total & 23 & 3370620,6 & & & \\
\hline
\end{tabular}

Les tests $\mathrm{F}$ font intervenir le rapport entre le carré moyen des écarts du facteur étudié sur celui du résidu.

Tableau VI. Effet de la fertilisation azotée (tous niveaux d'inoculation confondus), sur les biomasses aériennes (PA) et racinaires (RA) aux différents stades de développement du riz, après repiquage en pots, dans une expérience d'inoculation bactérienne. Les apports d'azote ont été pratiqués à 0,10 et 40 JAR.

\begin{tabular}{|c|c|c|c|c|c|c|c|c|}
\hline \multirow[t]{2}{*}{$\begin{array}{l}\text { Traitemen } \\
\text { azoté }\end{array}$} & \multicolumn{2}{|c|}{ 3OJAR } & \multicolumn{2}{|c|}{$\begin{array}{c}\text { Début floraison } \\
\text { 45JAR }\end{array}$} & \multicolumn{2}{|c|}{$\begin{array}{c}\text { Pleine floraison } \\
\text { 65JAR }\end{array}$} & \multicolumn{2}{|c|}{$\begin{array}{l}\text { Récolte } \\
\text { 85JAR }\end{array}$} \\
\hline & $P A$ & $R A$ & $P A$ & $R A$ & $P A$ & $R A$ & $P A$ & $R A$ \\
\hline Témoin & $20,5 \pm 4,4$ & $3,3 \pm 0,8$ & $33,1 \pm 8,4$ & $4,1 \pm 0,8$ & $49,6 \pm 15,7$ & $5,2 \pm 1,1$ & $57,5 \pm 9,2$ & $3,5 \pm 0,4$ \\
\hline $45 U$ & $33,5 \pm 13,7$ & $5,3 \pm 1,1$ & $68,9 \pm 21,8$ & $5,8 \pm 1,1$ & $84,0 \pm 21,8$ & $6,4 \pm 1,1$ & $96,7 \pm 12,8$ & $3,9 \pm 0,6$ \\
\hline $90 U$ & $\begin{array}{c}33,1 \pm 10,4 \\
n=4\end{array}$ & $\begin{array}{c}5,4 \pm 0,8 \\
n=12\end{array}$ & $\begin{array}{c}76,4 \pm 27,6 \\
n=4\end{array}$ & $\begin{array}{c}6,2 \pm 1,1 \\
n=12\end{array}$ & $\begin{array}{c}88,8 \pm 16,3 \\
n=4\end{array}$ & $\begin{array}{c}6,7 \pm 1,3 \\
n=12\end{array}$ & $\begin{array}{c}98,9 \pm 9,4 \\
n=8\end{array}$ & $\begin{array}{c}4,3 \pm 0,4 \\
n=24\end{array}$ \\
\hline Effet az & te NS & $\mathrm{S}$ & S & $\mathrm{S}$ & S & NS & $\mathrm{S}$ & $\mathrm{S}$ \\
\hline
\end{tabular}

Les valeurs PA (en g de matière sèche/pot) et RA (en g de matière sèche/poquet) sont des moyennes \pm intervalle de confiance (5\%) ; JAR : jours après repiquage; $n$ : nombre de répétitions par traitement ; NS : non significatif $(P>0,05), S:$ significatif $(P<0,05)($ voir tableau IV). 
Tableau VII. Effet de la fertilisation azotée sur les composantes du rendement à la récolte.

\begin{tabular}{ccccc}
$\begin{array}{l}\text { Traitement } \\
\text { azoté }\end{array}$ & $\begin{array}{c}\text { Poids de } \\
\text { 1000 grains }(g)\end{array}$ & $\begin{array}{c}\text { Nombre de panicules } \\
\text { par pot }\end{array}$ & $\begin{array}{c}\text { Nombre de grains } \\
\text { pleins par pot }\end{array}$ & $\begin{array}{c}\text { Rendement } \\
\text { (g par pot) }\end{array}$ \\
\hline Témoin & $22,1 \pm 2,1$ & $35,7 \pm 9,1$ & $1771 \pm 211,8$ & $38,9 \pm 5,7$ \\
$45 \mathrm{U}$ & $22,8 \pm 1,3$ & $44,5 \pm 11,7$ & $1797 \pm 352,4$ & $41,1 \pm 6,9$ \\
$90 \mathrm{U}$ & $22,3 \pm 1,3$ & $51,6 \pm 8,2$ & $2138 \pm 317,6$ & $47,6 \pm 7,4$ \\
& $n=8$ & $n=8$ & $n=8$ & $n=8$ \\
Effet azote & $\mathrm{NS}$ & $\mathrm{S}$ & $\mathrm{S}(\mathrm{P}=8,3 \%)$ & $\mathrm{S}(\mathrm{P}=7,2 \%)$
\end{tabular}

Les valeurs sont des moyennes \pm intervalle de confiance $(5 \%) ; n$ : nombre de répétitions par traitement ; NS : non significatif $(P>$ $0,1)$, S : significatif $(P<0,05)$ et, si $0,05<P<0,1$, la valeur de $P$ est précisée (voir tableau $V$ ).

Tableau VIII. Effet de l'inoculation du riz par Burkholderia vietnamiensis TVV75 (tous niveaux d'azote confondus) sur les poids de matières sèches des parties aériennes (PA) et racinaires (RA) aux différents stades de développement de la plante après repiquage en pot.

\begin{tabular}{|c|c|c|c|c|c|c|c|c|}
\hline \multirow[t]{2}{*}{$\begin{array}{l}\text { Traitemer } \\
\text { azoté }\end{array}$} & \multicolumn{2}{|c|}{$30 J A R$} & \multicolumn{2}{|c|}{$\begin{array}{c}\text { Début floraison } \\
45 J A R\end{array}$} & \multicolumn{2}{|c|}{$\begin{array}{c}\text { Pleine floraison } \\
\text { 65JAR }\end{array}$} & \multicolumn{2}{|c|}{$\begin{array}{l}\text { Récolte } \\
\text { 85JAR }\end{array}$} \\
\hline & $P A$ & $R A$ & $P A$ & $R A$ & $P A$ & $R A$ & $P A$ & $R A$ \\
\hline Témoin & $28,5 \pm 8,5$ & $4,6 \pm 0,8$ & $57,6 \pm 26,8$ & $5,3 \pm 0,9$ & $66,6 \pm 21,8$ & $5,3 \pm 0,9$ & $80,5 \pm 14,1$ & $3,4 \pm 0,3$ \\
\hline Inoculé & $\begin{aligned} 29,5 & \pm 10,2 \\
n & =6\end{aligned}$ & $\begin{array}{c}4,7 \pm 0,9 \\
n=18\end{array}$ & $\begin{array}{c}61,3 \pm 23,6 \\
n=6\end{array}$ & $\begin{array}{c}5,5 \pm 0,9 \\
n=18\end{array}$ & $\begin{aligned} 81,7 & \pm 20,9 \\
n & =6\end{aligned}$ & $\begin{array}{c}7,0 \pm 0,8 \\
n=18\end{array}$ & $\begin{array}{c}88,3 \pm 15,2 \\
n=12\end{array}$ & $\begin{array}{c}4,4 \pm 0,4 \\
n=36\end{array}$ \\
\hline $\begin{array}{l}\text { Effet } \\
\text { inoculat }\end{array}$ & NS & NS & NS & NS & $\mathrm{S}$ & $S$ & NS & $S$ \\
\hline
\end{tabular}

Les valeurs PA (en $\mathrm{g}$ de matière sèche/pot) et RA (en $\mathrm{g}$ de matière sèche/poquet) sont des moyennes \pm intervalle de confiance ; JAR : jours après repiquage ; $n$ : nombre de répétitions par traitement ; NS : non significatif $(P>0,05)$; $S$ : significatif $(P<0,05)($ voir tableau IV).

\section{Effet de l'inoculation sur le rendement et ses composantes à la récolte}

Les résultats concernant les composantes du rendement à la récolte apparaissent dans le tableau IX et l'effet de l'inoculation est présenté dans le tableau V. Contrairement à l'azoteengrais, l'inoculation a entraîné une augmentation significative $(P<0,05)$ du poids de 1000 grains $(+7 \%)$. Le nombre de grains pleins par pot est augmenté significativement $(P=6,2 \%)$, ainsi que le nombre de panicules $(P=5,6 \%)$. En conséquence, le rendement calculé est significativement plus élevé $(P<0,05)$ pour le traitement inoculé $(+20 \%)$ que pour le témoin. Bien que l'interaction "azote $\mathrm{x}$ inoculation" ne soit pas significative (tableau $V$ ), nous avons présenté, sur la figure 1 , les rendements calculés pour les 6 traitements. Cette figure illustre bien le gain de rendement à tous les niveaux d'azote, mais égale- ment l'économie potentielle que l'inoculation permet de réaliser. Pour un rendement de $45,5 \mathrm{~g}$ par pot, l'économie est environ de 50 unités d'azote, ce qui est considérable.

\section{DISCUSSION ET CONCLUSION}

À tous les stades de développement du riz, la fertilisation azotée a eu un effet sur les variables de croissance et de rendement mesurées, sauf sur le poids de 1000 grains. La croissance et les rendements calculés des plantes fertilisées sont plus élevées que ceux des témoins, ce qui indique que l'azote est le facteur limitant principal de la croissance du riz dans les conditions expérimentales utilisées.

L'ensemble des variables de développment du riz et la plupart des composantes du rendement sont augmentés significativement par l'inocula- 
Tableau IX. Effet de l'inoculation du riz par Burkholderia vietnamiensis TVV75 sur les composantes du rendement à la récolte.

\begin{tabular}{lcccc} 
Traitement & $\begin{array}{c}\text { Poids de } \\
1 \text { ooo grains }(g)\end{array}$ & $\begin{array}{c}\text { Nombre de panicules } \\
\text { par pot }\end{array}$ & $\begin{array}{c}\text { Nombre de grains } \\
\text { pleins par pot }\end{array}$ & $\begin{array}{c}\text { Rendement } \\
(g / p o t)\end{array}$ \\
Témoin & & & & \\
Inoculé & $21,6 \pm 0,9$ & $39,2 \pm 6,3$ & $1763 \pm 272,5$ & $38,7 \pm 5,6$ \\
& $23,2 \pm 1,2$ & $48,7 \pm 9,1$ & $2041 \pm 180,3$ & $46,4 \pm 4,2$ \\
Effet inoculation & $n=12$ & $n=12$ & $n=12$ & $n=12$ \\
& $\mathrm{~S}$ & $\mathrm{~S}(\mathrm{P}=5,6 \%)$ & $\mathrm{S}(\mathrm{P}=6,2 \%)$ & $\mathrm{S}$ \\
\hline
\end{tabular}

Les valeurs en $\mathrm{g}$ de matière sèche/pot sont des moyennes \pm intervalle de confiance ; JAR : jours après repiquage ; $n:$ nombre de répétitions par traitement; $S$ : significatif $(P<0,05)$, si $0,05<P<0,1$ la valeur de $P$ est précisée (voir tableau $V$ ).

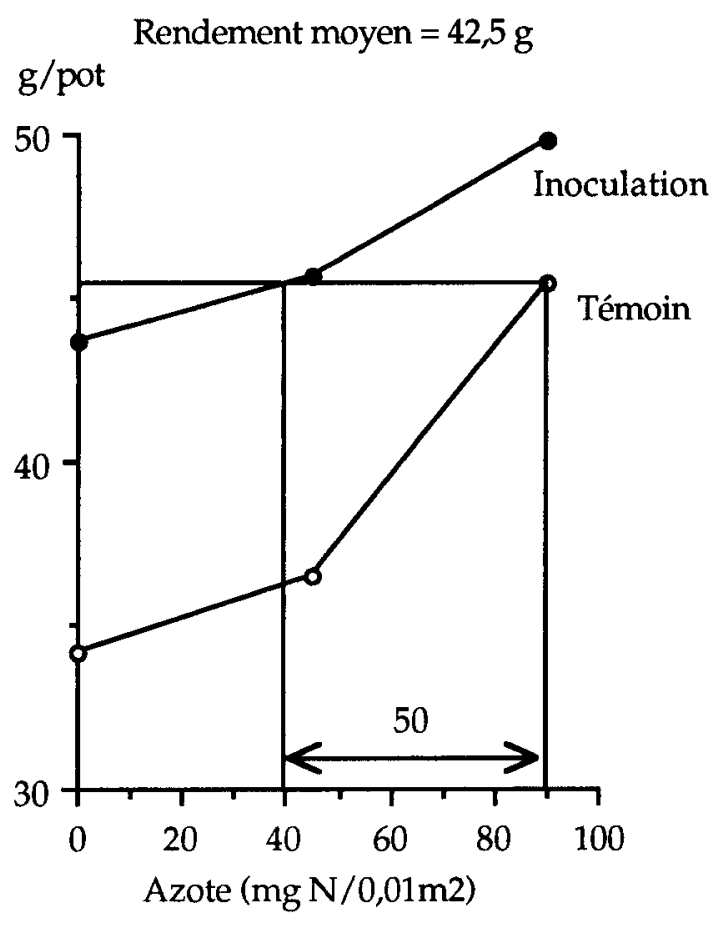

Azote (mg N/0,01 $\left.\mathrm{m}^{2}\right)$

Fig 1. Essai d'inoculation du riz par la souche Burkholderia vietnamiensis TVV75. Effet sur le rendement du riz avec le cultivar amélioré “OM5971" pour chacun des niveaux d'azote. Chaque point est la moyenne de 4 répétitions. Le gain d'azote entraîné par l'inoculation est représenté pour un rendement de $45,5 \mathrm{~g} / \mathrm{pot}$.

tion avec $B$ vietnamiensis TVV75. Cet effet positif de l'inoculation est déjà significatif au stade jeune plantule en pépinière. La hauteur des plantules et le nombre de talles herbacées sont nettement augmentés, de 8 et $12 \%$ respectivement. Ces plantes inoculées, plus vigoureuses, pourraient avoir un avantage sur les autres pour résister au stress du repiquage. Ceci n'a toutefois pas été testé dans cet essai, puisque des plantes comparables ont été choisies et réinoculées, avant d'être repiquées en pots. Après le repiquage, il semble que l'effet de l'inoculation ne soit pas immédiat et soit plus tardif que l'effet de l'engrais azoté puisqu'il faudra attendre la floraison pour que l'effet de l'inoculation soit significatif. Outre l'effet direct de l'inoculation bactérienne sur la croissance des racines, un effet indirect consécutif à une augmentation de la photosynthèse ne doit pas être écarté. L'effet précoce de l'inoculation sur les poids secs des racines et des tiges de plantules de maiis a pourtant déjà été rapporté consécutivement à l'introduction d'Azospirillum (Arsac et al, 1990). Ces auteurs ont également montré que la concentration bactérienne de l'inoculum affectait le bénéfice de l'inoculation avec un optimum à 2,5 x $10^{7} \mathrm{UFC} /$ plante. Dans notre expérience, nous n'avons pas testé cette variable. Bien que la concentration de $5 \times 10^{7}$ UFC/plante de nos conditions expérimentales semble donner des résultats, il conviendrait d'optimiser ce paramètre, en particulier pour envisager des applications agronomiques.

Nos données montrent que l'effet de l'inoculation sur la biomasse végétale demeure observable jusqu'à la récolte. Cependant, cet effet bénéfique n'apparaît pas au tallage ni en début de floraison. La mesure des biomasses aériennes et racinaires est, à ces stades actifs de croissance, plus sensible aux variations biologiques puisqu'elle intègre la hauteur des plantes et le nombre de talles. Les résultats apparaissent alors plus variables et statistiquement non significatifs.

Le résultat le plus notable est la traduction, en rendement final à la récolte, des effets positifs de l'inoculation observés au cours du développement du riz. En plus du nombre de panicules et du nombre de grains, le poids de 1000 grains est significativement augmenté, ce qui aboutit à 
un gain de $20 \%$ du rendement calculé des plantes inoculées par rapport au témoin.

Dans notre expérience, l'interaction entre l'inoculation et l'azote n'est pas significative, alors que, généralement, une augmentation plus importante est observée aux doses intermédiaires ou fortes. Cette observation a déjà été faite par de nombreux auteurs sur différentes céréales comme le riz à des niveaux de 80 à 120 unités d'azote (Kannaiyan et al, 1980 ; Omar et al, 1989 ; Omar et al, 1992), le maïs (Kalpunik et al, 1982) et le blé (Rai et Gaur, 1982).

Le riz cultivé dans nos conditions expérimentales en pots et à l'extérieur répond favorablement à l'inoculation par $B$ vietnamiensis TVV75. Les effets positifs précoces de l'inoculation persistent jusqu'à la récolte. Bien que le dénombrement de la souche inoculée n'ait pas été effectué aux différents stades de mesure des variables du rendement, il est très probable que c'est bien elle qui est responsable des effets observés, puisqu'elle possède un bon pouvoir colonisateur (elle appartient à la flore dominante). La méthodologie d'isolement de bactéries fixatrices et de leur inoculation à des plantes cultivées sur le même sol est très encourageante. La suite du travail, en cours de publication, concerne l'utilisation de l'inoculation du riz au champ en conditions réelles de riziculture intensive dans les sols sulfatés acides du Viêt-nam.

\section{REMERCIEMENTS}

Cette recherche s'est déroulée dans le cadre du contrat STD2 A0119F financé par IUE. Elle a été conduite en collaboration avec le CNRS-Viêt-nam (IBE, Hô Chi Minh Ville). Nous tenons à remercier particulièrement le $\mathrm{Pr}$ Ngo Ke Suong, directeur de l'IBE et le $\operatorname{Pr}$ Le Minh Triêt, de l'université d'agronomie IV de Hô Chi Minh Ville ainsi que l'étudiante Mai Ngoc Lan et les employés de la station agronomique appartenant à I'IBE pour leur assistance technique.

\section{RÉFÉRENCES}

Arsac JF, Lamothe C, Mulard D, Fages J (1990) Growth enhancement of maize (Zea mays L) through Azospirillum lipoferum inoculation: effect of plant genotype and bacterial concentration. agronomie 10, 640-654

Balasubramanian A, Kumar K (1987) Performance of Azospirillum biofertilizer in irrigated and rainfed upland rice. IRRN 12, 2-43
Boddey RM, Döbereiner J (1988) Nitrogen fixation associated with grasses and cereals. Recent results and perspectives for future research. Plant Soil 108, 53-65

Burbage DA, Sasser M (1982) A medium selective for Pseudomonas cepacia. Phytopathol Abstr 72, 706

Gaskins MH, Albrecht SL, Hubbell DH (1985) Rhizosphere bacteria and their use to increase plant productivity: a review. Agr Ecosyst Environ 12, 99-116

Gillis M, Trân Van V, Bardin R et al (1995) Polyphasic taxonomy in the solanacearum rRNA complex with a redefinition of the genus Burkholderia and the proposition of Burkholderia vietnamiensis $\mathrm{sp}$ nov for $\mathrm{N}_{2}$-fixing isolates from rice in Vietnam. Int $J$ Syst Bacteriol (sous presse)

Hebbar P, Davey AG, Merrin J, McLoughlin TJ, Dart PJ (1992) Pseudomonas cepacia, a potential suppressor of maize soil-borne diseases-seed inoculation and maize root colonization. Soil Biol Biochem 24, 999-1007

Jagnow (1987) Inoculation of cereal crops and forage grasses with nitrogen-fixing rhizosphere bacteria: Possible causes of success and failure with regard to yield response - a review. Z Pflanzenernähr Bodenk 150, 361-368

Jukevitch E, Hadar Y, Chen Y (1992) Differential siderophore utilization and iron uptake by soil and rhizosphere bacteria. App/ Environ Microbiol 58, 119-124

Kalpunik Y, Sarig S, Nur I, Okon Y, Henis Y (1982) The effect of Azospirillum inoculation on growth and yield of corn. Israel J Bot 31, 247-255

Kannaiyan S, Govindarajan K, Lewin HD (1980) Effect of foliar spray of Azotobacter chroococcum on rice crop. Plant Soil 56, 487-490

Kloepper JW, Lifshitz R, Zablotowicz RM (1989) Freeliving bacterial inocula for enhancing crop productivity. Trends Biotechnol 7, 39-44

Lemanceau $P$ (1992) Effets bénéfiques de rhizobactéries sur les plantes : exemple des Pseudomonas spp fluorescents. agronomie 12, 413-437

Lesinger T, Margraff R (1979) Secondary metabolites of the fluorescent Pseudomonas. Microbiol Rev 43, $422-442$

Lifshitz R, Kloepper JW, Kozlowski M et al (1987) Growth promotion of canola (rapeseed) seedlings by a strain of Pseudomonas putida under gnotobiotic conditions. Can J Microbio/ 33, 390-395

Lin W, Okon Y, Hardy RWF (1983) Enhanced mineral uptake by Zea mays and Sorghum bicolor roots inoculated with Azospirillum brasilense. Appl Environ Microbiol 45, 1775-1779

Michiels K, Vanderleyden J, Van Gool A (1989) Azospirillum-plant root associations: A review. Biol Fertil Soils 8, 356-368

Omar AMN, Heulin T, Weinhard P, Balandreau J (1989) Using the spermosphere model technique to describe the dominant nitrogen-fixing microflora associated with wetland rice in 2 Egyptian soils. Biol Fertil Soils 7, 158-163 
Omar N, Berge O, Shalaan SN, Hubert JL, Heulin T, Balandreau J (1992) Inoculation of rice with Azospirillum brasilense in Egypt. Results of 7 different trials between 1985 and 1990. Symbiosis 13, 281-289

Rai SN, Gaur AC (1982) Nitrogen fixation by Azospirillum spp and effect of Azospirillum lipoferum on the yield and $\mathrm{N}$-uptake of wheat crop. Plant Soil 69, 233-238

Rajamamohan Rao V, Jena PK, Adhya TK (1987) Inoculation of rice with nitrogen-fixing bacteria- problems and perspectives. Biol Fertil Soils 4, 21-26

Roger PA, Ladha JK (1992) Biological $N_{2}$ fixation in wetland rice fields. Estimation and contribution to nitrogen balance. Plant Soil 141, 41-55

Subba Rao NS, Tilak KVBR, Singh CS, LakshmiKumari M (1979) Response of a few economic spe- cies of graminaceous plants to inoculation with Azospirillum brasilense. Curr Sci 48, 133-134

Trân Van V (1989) Isolement et identification des bactéries fixatrices d'azote associées aux racines du riz poussant sur un sol de rizière du Viêt-nam. DEA écologie microbienne, univ Claude-Bernard, Lyon I, $47 \mathrm{p}$

Trân Van V (1994) Burkholderia vietnamiensis sp nov, une protéobactérie fixatrice d'azote de la rhizosphère du riz isolée d'un sol sulfaté acide : taxonomie et effets de l'inoculation sur la croissance et le rendement du riz. Thèse d'université, université de Nancy I, France, $360 \mathrm{p}$

Yabuuchi E, Kosado Y, Oyaizu H et al (1992) Proposal of Brukholderia gen nov and transfer of 7 species of the genus Pseudomonas homology group II to the new genus, with the type species Burkholderia cepacia (Palleroni and Holmes, 1981) comb nov. Microbiol Immunol 36, 1251-1275 